\title{
$\mathbb{A}$ Economics Bulletin
}

\section{Volume 30, Issue 2}

\section{Climate Risks, Seasonal Food Insecurity and Consumption Coping Strategies: Evidences from a Micro-level Study from Northern Bangladesh}

\author{
Mazbahul Golam Ahamad \\ Shahjalal University of Science and Technology
}

\author{
Rezai Karim Khondker \\ Shahjalal University of Science and Technology
}

\begin{abstract}
This paper examines the food insecurity status and coping strategies among the households in the Northern Bangladesh. A three stage stratified random sampling followed by a structured questionnaire was employed to collect primary data from nine different primary sampling units. Locally adjusted reduced consumption coping strategy index is used to quantify the food security status, especially for mainland and flood affected riverbanks of the study areas. Nine explanatory variables are considered for an interval regression to assess the impacts of these predictors on changing reduced consumption coping strategy index score. Moreover, body mass index of household heads and dependency ratio of respective households are analyzed to compare strata-wise food insecurity.
\end{abstract}

The authors are respectively MSS (Thesis) student and Professor (Head), Department of Economics, Shahjalal University of Science and Technology, Sylhet-3114. The views expressed in this paper are those of the authors alone and do not necessarily reflect the views of the institution. This study was conducted under a FAO (Food and Agriculture Organization) funded research project of NFPCSP programme, Bangladesh. We would like to express our sincerest thanks to Dr. Mohammad Mizanul Haque Kazal, Dr. Sayan Chakrabarty, Mr. Zahir Uddin Ahmed, Md. Khan Jahirul Islam, Mr. Romel Bhuiyan, Ms. Shaila Khan, Dr. Uttam Kumar Deb and Dr. A.K.M. Nazrul Islam for their helpful comments and suggestions.

Citation: Mazbahul Golam Ahamad and Rezai Karim Khondker, (2010) "Climate Risks, Seasonal Food Insecurity and Consumption Coping Strategies: Evidences from a Micro-level Study from Northern Bangladesh", Economics Bulletin, Vol. 30 no.2 pp. 1444-1459.

Submitted: Apr 07 2010. Published: May 18, 2010. 


\section{Introduction}

Food insecurity resulting from climate risk factors, in terms of basic four-fold FAO (2008) concepts--availability, access, utilization of food and stability of these three dimensions over time--within the framework of food poverty eradication, is a forward-looking idea. Accordingly, food insecurity is the ex-ante or forward-looking risk or probability that a household will, if currently food secure, fall below the food security line or if currently food insecure, will remain in food insecurity (Choudhuri et al. 2002). The term 'insecurity' refers to the relationship among food poverty i.e. failure to attain a certain well-being threshold ${ }^{1}$, risks and fails to manage those risks (Alwang et al. 2002). Thus the dynamic nature of household's food insecurity is an outcome from a variety of risk including climate as well as socioeconomic factors that are: riverbank erosion, damaged crop production in flood-prone areas, seasonal unemployment and an inability to manage those risks due to income as well as resource constraints (FAO 2008). To combat food insecurity objectives to be accomplished, all four dimensions must be consummated simultaneously.

The seasonal food insecurity concept falls between chronic (long-term) and transitory (shortterm) food shortage (FAO 2008). Chronic food insecurity is usually predictable and follows a sequence of known events and time bounds (Uddin 2006). Notwithstanding, as seasonal food insecurity is of short duration it can also be seen as perennial, transitory food insecurity. It occurs when there is a downward cyclical pattern of availability and access to food (FANTA 2007). These are accompanying with seasonal fluctuations of climatic risks, coping strategies, work opportunities as labor demand and family expenditures for foods (Rayhan and Grote 2010). At the household level marginal land ownership, dependency of wage labour, water scarcity for irrigation, degradation of cultivable land, loss of farm and off-farm jobs, indebtedness to local money lenders, social instability, price fluctuation of necessary commodities etc. are the main risk factors of food insecurity (Arun 2006). Uddin (2006) also explains an attempt to eradicate a seasonal-cum-chronic poverty in the northwestern part of Bangladesh focusing income deficiency through 'protection nets' in the most vulnerable regions. Moreover, Holmes et al. (2008) finds a significant relation between the impact of various social safety net programmes and agricultural growth in Bangladesh.

\subsection{Seasonal Food Insecurity and Risk Factors}

The Bangladesh Poverty Map $2009^{2}$ is an attempt to estimate poverty at lower administrative levels (Upazila). It is intended to enable economic analysts and policymakers to recognize regional geo-economic inequality and also the food security status. Seasonal food insecurity occurs frequently during the lean periods of the year, from mid-September to mid-November in Northern regions of Bangladesh. And in this context, households' per capita income falls, and limited access to foodgrains diffuses over rural poor and landless as well as marginal land-owning families, concentrated in greater Rangpur area (that are Kurigram, Gaibandha, Nilphamari, Lalmonirhat) and some part of Jamalpur district (VAM, WB and BBS 2009) (See Annex A). This occurs due to the incidences of extreme poverty, lack of income and consumable resources. Significant intra-household disparity and discrimination in food access also exists, especially in environmentally and economically vulnerable riverine northern domain of Bangladesh, situated in Tista and Jamuna basin that are known to be food insecured zones. Widespread flooding in July and August intensify the crisis every year (Zug 2006b). In accordance with the World Food Program's estimation, 80 to 90 percent of these

\footnotetext{
${ }^{1}$ See Christiaensen and Boisvert (2000).

${ }^{2}$ A research conducted by Bangladesh Bureau of Statistics (BBS) and World Bank (WB) in collaboration with the Vulnerability Analysis and Mapping (VAM) unit of the UNWFP, revealed at 2009.
} 
people are agricultural day labourers. They are identical groups, numbering 20 to 30 million, who are the ultra-poor and simply do not have the access to food and social safety net programs. Hence, one million children in Bangladesh are at risks from acute malnutrition and 500,000 pregnant and nursing women are also extremely vulnerable ${ }^{3}$.

The Northern region, especially greater Rangpur district is a food surplus area ${ }^{4}$ (Kabir 2005). A significant correlation between harvesting periods and labour demand exists among these food insecure districts and agriculture sector cannot provide enough employment opportunities for the surplus agricultural labour force that leads to a very low wage rate (BDT 50.9 per Day) (BBS 2005). The main reason for the low employment opportunity is the lack in agricultural product diversification and low production due to changes in the climatic factors such as low rainfall, river erosion, extended dry season in these districts. Since the landless poor mostly survive on wage labour (agriculture based), employment opportunities and income level fall in the lean periods, and they become trapped in a cyclical phenomenon of food poverty and hunger. More than one-third of the households in these zones face food shortage throughout the year and another one-third faces temporary food shortage during the year round (Shahabuddin and Ali 2006).

Topographical status and climate risks make these areas ecologically vulnerable to destabilizing variations including floods, riverbank erosions, drought spells, and cold waves (CARE and WFP 2005), all of which occur more frequently and intensely than in other regions. In the recent years with meticulous pessimistic weather conditions (drought, cold spells, early floods in August to September) destroy significant part of the Aman (local rice variety) rice production. Unexpected low rainfalls leading to swollen rivers and increased erosion or flooding destroy houses hitting cash-strapped poor households, loss of stored food stocks. The unanticipated climatic shocks that trigger food insecurity and destroye household assets, reduces labour demands; and hence income level, which reduces per day meal taken. All these aggregated vulnerability endures the hardcore poor in the food insecurity cycle.

The flood affected riverbanks (and chars) ${ }^{5}$ in northern Bangladesh in between Jamuna and Teesta basin have a big influence on the livelihoods of many people in Greater Rangpur districts belonging to the poorest resolution areas in the entire Bangladesh (Zug 2006a). People's life in the flood affected riverbanks (chars) is determined by the nature of the rivers which are confronted with floods spanning from July to August preceding the locally lean period every year. In these period livelihoods in the chars is a so tight and only capable household leave to mainland, living from agricultural day-laboring, share cropping and share raring for absentee landlords. The char dwellers and those who live along with the banks of the rivers are also confronted with riverbank erosion. Affected households are being displaced and often settled on another char land or on the government-owned embankments (Zug 2006b).

In these contexts, households need to rely on less preferred food, borrow from neighbours, purchase food on credit (borrowing with high interest rate), or gather food from natural/wild sources when the families do not have enough money to buy. Hardship comes when people are induced to sell agricultural products, livestock and fixed/movable assets or take

\footnotetext{
3 According to World Food Program's (WFP) these data revealed at a report 2004. Current data may be fluctuated, but it gives a rigorous overlook about the curse of food insecurity.

${ }^{4}$ According to Kabir, greater Rangpur had a surplus in rice and wheat of 37\% in 1999/2000.

${ }^{5}$ The chars are formed as a result of river erosion and silt deposition, and are surrounded by water throughout the year. Source: http://www.clp-bangladesh.org
} 
temporary migration. Income distortions, in whatever form, suffered by parents leads to lower food stock/lack of access to required nutritional needs and aggravating family poverty, which in turn would make their children more vulnerable and therefore, leads to a phenomenon of perpetual poverty.

\subsection{Rationale, Objectives and Limitations of the Study}

Food insecurity and related coping strategies deserve special attention in this study mainly for two reasons: first, although food insecurity represents the traditional seasonal problem in lean periods, its persistence over time gives it a flavor of chronicity and/or intergenerational transmission of poverty (Shahabuddin and Ali 2006). Secondly, food insecurity is largely confined to ecologically vulnerable parts of northern districts with, of course, yearly variations of its severity. ${ }^{6}$ The major objectives of this study are: firstly, to understand the differences in the magnitude of food insecurity and consequent food vulnerability among people from mainland vis-à-vis people in flood affected riverbank (especially chars) households. Secondly; the consumption coping strategies are to mitigate (ways to limit the effects) and adapt (ways to adjust lifestyles to suit the changed conditions) with climate risk factors, as a determinant of food insecurity. This empirical study analyses how climatic risk factors affect food insecurity. It also focuses on the coping strategies of the affected households.

The limitations of the study are mostly associated with the size and structure of the sample design. Though the overall response rate was satisfactory but more detailed interdisciplinary research is needed for complete understanding on food insecurity in the study areas.

\section{Data and Model}

\subsection{Survey and Sample Design}

The primary survey on the households was conducted on food insecure households at Nothern region of Bangladesh. Those households were treated as elementary units of the target population where, at least one member of the household is under voluntary group feeding $\left(\mathrm{VGF}^{7}\right)$ program and poor but not getting VGF. First, an area frame was chosen from the study area situated in the Tista and Jamuna basin that are known to be food insecure zone. List frame was constructed according to the list of affected households provided by the concerned district authorities and NGOs working with them. The major features of sample design included target sample size, sample allocation, sample frame and listing, choice of domains, sampling stages and stratification.

The primary objective of the sample design for the study was to produce statistically reliable estimates of the indicators, at the study areas (primarily classified as mainland and flood affected riverbank). Lower administrative unit (See Annex $A$ ) was defined as the sampling domain or primary sampling unit (PSU, also called Strata).

\footnotetext{
${ }^{6}$ Putting food insecurity in a time perspective of the last fifteen years, it has been observed that one of the important changes which have taken place over the 1990-2005 periods is the general reduction of the seasonal poverty across Bangladesh and its continued persistence in the ecologically vulnerable areas of northern districts (PPRC Report, 2005).

7 Through voluntary group feeding (VGF) programme, vulnerable people get supports in various forms comprising financial and food aids. This program is also helping the development of rural infrastructure as well as livelihoods of the poor people. Source: http://www.bangladesh.gov.bd
} 


\subsection{Sample Size Determination}

To determine the sample size out of 1876 households those who were the beneficiary of social safety net programmes and households below the poverty line applied the following way.

$$
n=\frac{\sum \frac{N_{i}^{2} P_{i}\left(1-P_{i}\right)}{w_{i}}}{N^{2} V_{o}+\sum N_{i} P_{i}\left(1-P_{i}\right)}
$$

Where, $n$ is the required sample, expressed as number of households; $N_{i}$ is the total households of the study area (beneficiary of social safety net programmes and households below the poverty line), $P_{i}$ is the population proportion in the $i^{\text {th }}$ stratum; $w_{i}$ is the PSU weight; $V_{o}$ is the $V_{o}=V\left(p_{s t}\right)$. For the calculation, $P_{i}$ was assumed to be 92 percent in the study area in accordance of the previous study and field survey.

A structured questionnaire was administered including the reduced form consumption coping strategy index where heights and weights were measured. Annex D1 and Annex D2 show the calculation of sampling distribution.

\subsection{Reduced Consumption Coping Strategies Index}

Reduced consumption coping strategies index (RCCSI) explains a quick qualitative look and rank on food insecurity mitigating options. Reduced consumption CSI is a geologically adjusted analyzing index tool that provides real-time (at lean period actually) information to researchers, which is relatively quick and easy to use, can be administered and correlated subsequently with more complex measures of food insecurity at regional level. Even though a comprehensive investigation of households' food insecurity would require a detailed consideration of livelihoods and assets, the RCCSI is entirely satisfactory as a rapid indicator of household food insecurity status.

A set of sample questions were developed to capture household's basic consumption related coping responses to inadequate economic access to food in a given area (affected zone) due to climatic as well as socio-economic factors, based on the list of coping behaviors. First step in the questionnaire design process is to identify the local coping strategies in the study areas. All these questions fall into four basic categories. Those are change in consumption, shortterm actions to raise food availability, short-term measures to decrease number of people (especially adult persons) to feed, rationing quantity, or managing the food deficit by other ways.

At step two we counts frequency, the relative frequency of strategies, that are every day in a week (score=7), 3-6 days per week (score $=4.5), 1-2$ days per week $($ score $=1.5) 1$ day per week (score $=0.5)$ and never $($ score $=0)$. Step 3 explains the coping strategies severity that includes categorizing and weighting the coping strategies. RCCSI depends on counting up coping behaviours that are not equal in food severity. Various strategies (10 different strategies considered in this study based on field-survey and pre-tests of the questionnaire) are weighted and multiplied by a weight that presents their severity before being added collectively.

At step 4, RCCSI scoring procedure starts that combining frequency and severity for analysis. The higher the RCCSI raw index score, the more food insecure a household is. This means that, more often any (or with another) coping strategy is used, the higher the index score should be for that household strategy (FAO 2003); and secondly, the more severe a strategy 
is, the higher the weight should be for that whole ranked strata (primary sampling unit, PSU). RCCSI as mentioned here is a measure of food insecurity that is higher the score, the greater is the food insecurity. A complete procedure is stated at Annex $C$.

\subsection{Econometric Methodology}

An interval regression model was considered that includes reduced consumption coping strategies index (RCCSI) score as a dependent variable using nine explanatory variables (See Annex D1). However, the RCCSI score is not totally accurate because of the variability of responses and respondent's biases as well, we only consider data on the RCCSI ranges: 30$50,50-70,70-90,90-110,110-130,130-150,150-170,170-190,190-210$ and $210->$. It is notable that the extreme values of the categories on either end of the range are either leftcensored or right-censored while the other categories are interval censored, that is, each interval is both left and right censored. To analyses this we need a generalization of censored regression known as interval regression (UCLA 2010). The model is:

(1) RCCSI Score Ranges $=f$ (Set of explanatory variables $)+\varepsilon$

(2) Range Score (Lower, Upper) $=\alpha+\beta_{1}$ hhh_ps_l $+\beta_{2}$ hhh_age $+\beta_{3}$ pcmfe_mp $+\beta_{4}$ tot_mem $+\beta_{5}$ paddy_d $+\beta_{6} p \_a s s \_v a l+\beta_{7} \operatorname{ssnp} g o v t \_l+\beta_{8} h h \_l o a n \_l+\beta_{9}$ river_bank_l $+\varepsilon$

Annex D (from Annex D1 to Annex D4) represents the total procedure of interval regression model comprising sources and definition, summery statistics, correlation matrix of model variables and econometric estimation.

\subsection{Body Mass Index (BMI ${ }^{8}$ ) and Dependency Ratio (DR)}

Body mass index is a statistical measure which compares a person's weight and height and acts as an indication of chronic deficiency in adults. Food insecurity is common at all levels of BMI and there was no clear association between food insecurity and obesity (BMI $>30)$ (Gulliford et al. 2003), but a paradoxical relationship between these two variables has also been reported (Dinour et al. 2007). In fact, adults who experience underweight $(\mathrm{BMI}<18.5)$ are more likely to be lower income earners because of the high prevalence of agricultural wage labour and low demand at slack seasons, where healthy persons are prioritized.

The dependency ratio of households is the ratio of household members who are not working (people aged 0-14 and over 65) to those that are working (people aged 15-64, income earners), may affect household's food security status with some degree of economic estimation. DR is expected to decrease the food security of households as it increases. However, it is considerable since it is possible that all members of a household to be working but their total income may be small.

\section{Empirical Results}

Reduced consumption coping strategy index has two possible applications in food security encoding, especially monitoring the short-term household food insecurity in local lean periods and as an early warning indicator. This study deals with local as well as reduced consumption coping strategy index that are the general strategy to mitigate food insecurity.

\footnotetext{
${ }^{8} \mathrm{BMI}$ (in SI unit) $=$ Weight $(\mathrm{Kg}) / \mathrm{Height}\left(\mathrm{m}^{2}\right)$.
} 
The questions used in preparing the index (RCCSI) sets on the basis of degree of local severity and priority. Annex $C 5$ shows the strata besides riverbank (Min. value=39) represents high value of minimum score than mainland areas (Min. value $=30$ ). The reason behind this situation's that households face more anticipated and unanticipated risks due to climatic events and consequences on consumption behaviour through income pattern as well as livelihoods. That is why they are more food insecure compare to people from mainland. The average score of RCCSI reflects the same. Most viewed coping strategies in the study areas are: 'rely on less preferred and less expensive foods', 'gather wild food, hunt or harvest immature crops', and 'reducing number of meals eaten in a day'.

The interval regression model predicts reduced consumption coping strategy index (RCCSI) from a set of independent variables (See Annex D4) is statistically significant (Wald Chisquare $=39.57, \mathrm{df}=9$, Prob $>0.000$ ). The ancillary statistic (/Insigma) is equivalent to the standard error of estimate in OLS regression. The category variables retained in the interval regression model considered by the inclusion criteria, explains better understanding (/Insigma $=3.52$ at 0.00 level) about the variation in RCCSI score.

Household heads with primary education are more food secured (significant at 5\% level) than illiterate counterparts. Moreover, household heads' age has a negative influence on RCCSI score, that is their food insecurity status decreases with age. Food insecurity is also negatively related to per capita monthly food expenditures at lean periods. Fulfillments of paddy demand in a year (in days) by own production and total value of asset (for production purposes) of households are statistically significant at $0 \%$ level. Due to unexpected variations of climatic factors, the paddy production decreases and other forms of assets also reduce (for both livelihood and production purpose).

Government has various food insecurity reduction programmes over the affected region. The study reveals that households under government's social safety net programmes are more food insecure than others. Annex D4 shows the statistically significant (at 5\% level), positively associated social safety net programme of government with reduced consumption coping strategy index. Coefficient of total outstanding loan indicates a positive but statistically insignificant influence on RCCSI.

The important findings from this analysis is that the households resided near the riverbank are more food insecure than those who resided in the mainland. The coefficient has a strong statistical significance (at 5\% level), means a positive impact on RCCSI score. This shows that climatic risk factors such as riverbank erosion, flooding or sandy cultivable land affects those households. Annex D3 shows the correlation matrix of the interval regression model.

Annex $E$ shows the strata-wise BMI with ranking $(1=$ underweight, $2=$ healthy weight, $3=$ overweight). Data are analyzed for $89 / 106$ (84\%) of eligible respondents because of the absence at home during data collection. The percentage of underweight household heads at mainland and riverbank areas are $54.24(\mathrm{n}=32)$ and $46.67(\mathrm{n}=14)$, respectively. Previous studies also reveal the significant correlation between physical soundness and income pattern of household heads. In this regard, 51.68\% household heads are underweight, can play a negative role in reducing food insecurity. Annex $F$ represents the graphical representation of strata-wise dependency ratio. In this figure strata no. 3 and 9 represent the highest ratios of $\mathrm{DR}$, reflect that respective strata consists high proportion of non-earning members. 


\section{Conclusions and Policy Recommendations}

This study reveals that reducing food intake throughout the lean periods (over 80 percent) is one of the common features of seasonal food insecurity in the Northern parts of Bangladesh. Moreover, climatic factors have also direct and significant impacts on seasonal food insecurity in the slack seasons of a year. Therefore, the response actions should be taken on the basis on pre-crisis (early) warning systems. In view of the upcoming momentum of food insecurity, short term measures (food aid under social safety nets, employment generation activities, etc.) will fulfill the basic food demand, at early of September. Apart from these, it increasing resilience capacity to preliminary shocks and stresses generated from socioeconomic constraints and subsequent fluctuations of food intake.

Since food insecurity is an outcome from a sort of risks, policy makers should broaden their efforts to analyze the determining factors of food insecurity addressing time fixed action plans to reduce the degree of severity and enhance the ability to cope up with different preventive strategies. Minimum calorie intake should be ensured for the vulnerable groups through linked channels of connectivity involving strategic or buffer stock of food grains at the Upazila level, by convenient supply chain management and equitable allocation of sufficient food aid.

\section{References}

Arun, K. and Keshav, M. (2006) "Food Insecurity and Coping Strategies in Rural Areas of Nepal: A Case Study of Dailekh District in Mid Western Development Region: Nepal: Journal of International Development and Cooperation, Vol.12, No.2, 2006, pp. $25-45$.

Alwang, et al. (2002) "Vulnerability: A view from different disciplines." USA: Social Protection Discussion Paper Series Number. SP 0115. World Bank, Washington, D.C.

BBS. (2005) "Statistical Yearbook of Bangladesh 2005." Dhaka: Bangladesh Bureau of Statistics.

CARE. and WFP. (2008) "The Coping Strategy Index: Field Method Manual." USA: Cooperative for Assistance and Relief Everywhere and World Food Programme.

Chaudhuri, S., Jalan, J. and Suryahadi , A. (2002) "Assessing household vulnerability to poverty: A methodology and estimates for Indonesia." USA: Department of Economics, Discussion Paper No. 0102-52. Columbia University.

Christiaensen, L. and Boisvert, R. (2000) "On Measuring Household Food Vulnerability: Case Evidence from Northern Mali." New York: Department of Agricultural, Resource, and Managerial Economics Cornell University, Ithaca.

Dinour, L. et al. (2007) "The Food Insecurity -Obesity Paradox: A Review of the Literature and the Role Food Stamps May Play”, J AM Diet Assoc.2007; 107:1952-1961. 
FAO. (2003) International Workshop on "Food Security in Complex Emergencies: building policy frameworks to address longer-term programming challenges. Tivoli: 23-25 September.

FAO. (2008) "The State of Food Security in the World: High Food Prices and Food securityThreats and opportunity." Italy: Food and Agriculture Organization of the United Nations.

Gulliford, M.C., Mahabir, D. and Rocke, B. (2003) "Food insecurity, food choices, and body mass index in adults: nutrition transition in Trinidad and Tobago" International Journal of Epidemiology 32, pp. 508-516.

Holmes, et al. (2008) "Extreme poverty in Bangladesh: Protecting and promoting rural livelihoods." UK: Overseas Development Institute (ODI).

Kabir, M. (2005) "Conceptualization and Measurement of Food Insecurity: The context of Bangladesh.” BIISS Journal 26(1), pp.55-90, pp. 87.

FANTA. (2007) "Malawi Food Security Programming Strategy FY 2008-2014". Food and Nutrition Technical Assistance Project, Washington, D.C.: Academy for Educational Development (AED).

Rayhan, I. and Grote, U. (2010) "Crop Diversification to Mitigate Flood Vulnerability in Bangladesh: An Economic Approach", Economics Bulletin, Vol. 30 no.1 pp. 597-604.

Shahabuddin, Q. and Ali, Z. (2006) "Natural Disasters, Risks, Vulnerability and Persistence of Poverty: An Analysis of Household Level Data." Bangladesh Institute of Development Studies (BIDS). Dhaka, Bangladesh: PRCPB Working Paper No. 15.

UCLA. (2010) Stata Data Analysis Examples: Interval Regression. Academic Technology Services, Statistical Consulting Group. Accessed from http://www.ats.ucla.edu/stat/ stata/ dae/intreg.htm/ (Accessed March 30, 2010)

Uddin, J. (2006) "Programmed Initiatives for Monga Eradication (PRIME): Design and Challenges." Dhaka: Accessed from http://www.inm.org.bd/seminar/sem _monga/ document/summary/jashimuddin.pdf

VAM., WB. and BBS. (2009) "Bangladesh Poverty Map 2009.” Dhaka: Bangladesh Bureau of Statistics and Vulnerability Assessment and Mapping Unit.

Zug, S. (2006a) "Monga - Seasonal Food Insecurity in Bangladesh - Bringing the Information Together.”. Dhaka: The Journal of Social Studies, No. 111, July-Sept. 2006, Centre for Social Studies.

Zug, S. (2006b) “Monga - Seasonal Food Insecurity in Bangladesh.” Dhaka: NETZ. 


\section{Annexure}

Annex A: Upper and Lower Poverty Line

\begin{tabular}{llcc}
\hline District & Upazila & $\begin{array}{c}\text { \% Poor } \\
\text { (Upper Poverty Line) }\end{array}$ & $\begin{array}{c}\text { \% Extreme Poor } \\
\text { (Lower Poverty Line) }\end{array}$ \\
\hline Kurigram & Bhurungamari & 68.20 & 52.00 \\
Kurigram & Char Rajibpur & 73.90 & 58.80 \\
Kurigram & Chilmari & 69.00 & 53.10 \\
Kurigram & Phulbari & 65.80 & 49.10 \\
Kurigram & Kurigram Sadar & 66.10 & 49.90 \\
Kurigram & Nageshwari & 70.30 & 55.00 \\
Kurigram & Rajarhat & 64.00 & 47.30 \\
Kurigram & Raumari & 73.50 & 58.10 \\
Kurigram & Ulipur & 66.90 & 50.00 \\
\hline District Average & 68.63 & 52.59 \\
\hline Gaibandha & & 53.04 & 36.07 \\
Kurigram & & 68.63 & 52.59 \\
Lalmonirhat & & 53.46 & 33.82 \\
Nilphamari & & 70.15 & 55.00 \\
Food Insecured Areas Average & 61.32 & 44.37 \\
\hline
\end{tabular}

Source: Bangladesh Poverty Map, VAM, WB and BBS, 2009.

Annex B: Sample Design (Three Stage Stratified Random Sampling)

\begin{tabular}{crrrrrc}
\hline PPS & $\mathrm{Ni}$ & $\mathrm{Wi}$ & $\mathrm{Pi}$ & $\mathrm{NiPi}(1-\mathrm{Pi})$ & $\mathrm{Ni}^{2} \mathrm{Pi}(1-\mathrm{Pi}) / \mathrm{Wi}$ & Sample No. \\
\hline 1 & 171 & 0.091151 & 0.92 & 12.5856 & 23610.5856 & 10 \\
2 & 286 & 0.152452 & 0.92 & 21.0496 & 39489.0496 & 16 \\
3 & 306 & 0.163113 & 0.92 & 22.5216 & 42250.5216 & 17 \\
4 & 172 & 0.091684 & 0.92 & 12.6592 & 23748.6592 & 10 \\
5 & 188 & 0.100213 & 0.92 & 13.8368 & 25957.8368 & 11 \\
6 & 253 & 0.134861 & 0.92 & 18.6208 & 34932.6208 & 13 \\
7 & 157 & 0.083689 & 0.92 & 11.5552 & 21677.5552 & 9 \\
8 & 205 & 0.109275 & 0.92 & 15.088 & 28305.088 & 12 \\
9 & 138 & 0.073561 & 0.92 & 10.1568 & 19054.1568 & 8 \\
\hline & 1876 & & & 138.0736 & 259026.0736 & 106 \\
\hline
\end{tabular}

Note: $Z=1.96$

$\mathrm{E}=0.05$

$\mathrm{V}_{0}=0.00065$

$\mathrm{N}^{2} \mathrm{~V}_{0}=2290.306$

So, $n=106$

Source: Authors' Calculations, 2010. 
Annex C: Constructing and using the RCCSI Tool

Annex C1: Coping Strategies: Getting the Right List for the Study Areas (Step 1)

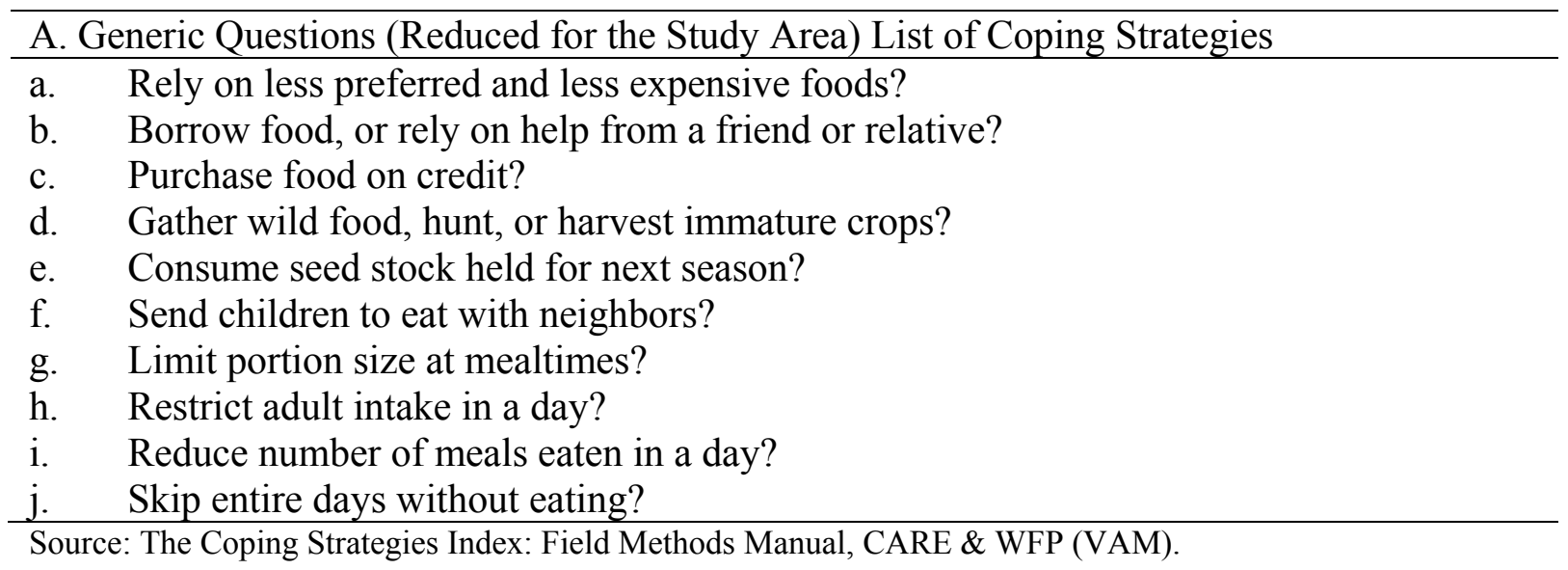

Annex C2: Severity: Categorizing and Weighting the Strategies (Step 2)

\begin{tabular}{lccccccccccc}
\hline \multicolumn{1}{c}{ Consumption Coping Strategies Grouped and Ranked by Focus Groups } \\
\cline { 2 - 11 } \multicolumn{1}{c}{ Strategies } & 1 & 2 & 3 & 4 & 5 & 6 & 7 & 8 & 9 & Avg. & Ranking \\
\hline a. Less preferred & 1 & 2 & 1 & 1 & 1 & 1 & 1 & 1 & 1 & 1.4 & 2 \\
b. Borrow & 4 & 3 & 3 & 4 & 4 & 4 & 4 & 3 & 3 & 3.6 & 4 \\
c. Buy on credit & 3 & 4 & 4 & 4 & 4 & 4 & 4 & 4 & 4 & 3.9 & 4 \\
d. Wild food & 5 & 6 & 6 & 5 & 6 & 5 & 6 & 6 & 6 & 5.7 & 6 \\
e. Eat seed stock & 5 & 6 & 5 & 6 & 5 & 5 & 5 & 5 & 6 & 5.5 & 6 \\
f. HH eat elsewhere & 4 & 4 & 4 & 3 & 3 & 3 & 4 & 4 & 3 & 3.6 & 4 \\
g. Limit portion & 6 & 6 & 6 & 6 & 6 & 5 & 5 & 6 & 6 & 5.8 & 6 \\
h. Restrict adult intake & 7 & 8 & 8 & 8 & 8 & 7 & 8 & 8 & 7 & 7.7 & 8 \\
i. Reduce meals & 1 & 2 & 2 & 2 & 2 & 2 & 2 & 2 & 2 & 1.9 & 2 \\
j. Skip days & 8 & 8 & 8 & 8 & 8 & 8 & 8 & 8 & 7 & 7.9 & 8 \\
\hline
\end{tabular}

Source: Field Survey and Authors' Calculations, 2010.

Annex C3: Scoring: Combining Frequency and Severity for Analysis (Step 3)

Assigning numeric values to relative frequency...

The relative frequency categories....

All the time? Pretty often? Once in a while? Hardly at all? Never

Every day 3-6 Days/week 1-2 Days/week <1 Day/week 0 Day/week

....are scored according the mid-point value of the range of each category:

\begin{tabular}{lllll}
\hline 7 & 4.5 & 1.5 & 0.5 & 0 \\
\hline
\end{tabular}

Source: The Coping Strategies Index: Field Methods Manual, CARE \& WFP (VAM).

\footnotetext{
${ }^{9}$ Consumption coping strategies ranked based on field survey, pre-test of the questionnaire and focus group discussion (FGD).
} 
Annex C4: An Actual Example of Calculating a Household RCCSI Score (Step 4)

\begin{tabular}{|c|c|c|c|c|c|c|c|c|}
\hline $\begin{array}{l}\text { In the past } 30 \text { days, if there have been } \\
\text { times } \\
\text { when you Relative Frequency did not } \\
\text { have } \\
\text { enough food or money to buy food, how } \\
\text { often has your household had to: }\end{array}$ & 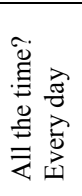 & 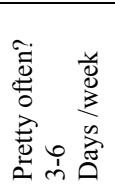 & 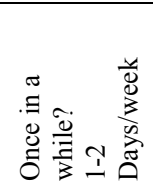 & 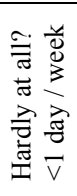 & 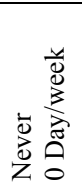 & 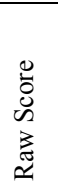 & 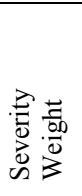 & 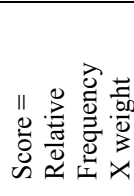 \\
\hline Relative Frequency Score & 7 & 4.5 & 1.5 & 0.5 & 0 & & & \\
\hline $\begin{array}{l}\text { a. Rely on less preferred and less } \\
\text { expensive foods? }\end{array}$ & 0 & 1 & 0 & 0 & 0 & 4.5 & 2 & 9.0 \\
\hline $\begin{array}{l}\text { b. Borrow food, or rely on help from a } \\
\text { friend or relative? }\end{array}$ & 0 & 0 & 1 & 0 & 0 & 1.5 & 4 & 6.0 \\
\hline c. Purchase food on credit? & 0 & 0 & 0 & 1 & 0 & 0.5 & 4 & 2.0 \\
\hline $\begin{array}{l}\text { d. Gather wild food, hunt, or harvest } \\
\text { immature crops? }\end{array}$ & 0 & 0 & 0 & 1 & 0 & 0.5 & 6 & 3.0 \\
\hline $\begin{array}{l}\text { e. Consume seed stock held for next } \\
\text { season? }\end{array}$ & 0 & 0 & 0 & 0 & 0 & 0.0 & 6 & 0.0 \\
\hline $\begin{array}{l}\text { f. Send household members to eat } \\
\text { elsewhere? }\end{array}$ & 0 & 0 & 0 & 0 & 0 & 0.0 & 4 & 0.0 \\
\hline g. Limit portion size at mealtimes? & 0 & 0 & 1 & 0 & 0 & 1.5 & 6 & 9.0 \\
\hline $\begin{array}{l}\text { h. Restrict consumption by adults in order } \\
\text { for small children to eat? }\end{array}$ & 0 & 0 & 0 & 1 & 0 & 0.5 & 8 & 4.0 \\
\hline $\begin{array}{l}\text { i. Reduce number of meals eaten in a } \\
\text { day? }\end{array}$ & 0 & 0 & 0 & 0 & 0 & 0.0 & 2 & 0.0 \\
\hline j. Skip entire days without eating? & 0 & 0 & 0 & 0 & 0 & 0.0 & 8 & 0.0 \\
\hline Total Household Score & & & um down th & tals $\mathrm{f}$ & indiy & strat & & 33.0 \\
\hline
\end{tabular}

Source: The Coping Strategies Index: Field Methods Manual, CARE \& WFP (VAM).

Annex C5: Strata-wise RCCSI Score

\begin{tabular}{lcccrrr}
\hline \multirow{2}{*}{ Strata Type } & Strata & $\begin{array}{c}\text { Minimum } \\
\text { Score }\end{array}$ & $\begin{array}{c}\text { Maximum } \\
\text { Score }\end{array}$ & $\begin{array}{r}\text { Mean } \\
\text { Score }\end{array}$ & $\begin{array}{r}\text { Median } \\
\text { Score }\end{array}$ & \% of Total \\
\hline \multirow{5}{*}{ Mainland } & 1 & 30 & 179 & 97.80 & 103.00 & $9.4 \%$ \\
& 2 & 39 & 204 & 104.25 & 108.00 & $15.1 \%$ \\
& 3 & 39 & 206 & 120.59 & 123.00 & $16.0 \%$ \\
& 6 & 62 & 150 & 100.07 & 94.00 & $13.2 \%$ \\
& 7 & 42 & 152 & 115.89 & 120.00 & $8.5 \%$ \\
\hline \multirow{5}{*}{ Riverbank } & Total & 30 & 206 & 108.18 & 108.00 & $62.3 \%$ \\
& 4 & 39 & 206 & 116.30 & 119.50 & $9.4 \%$ \\
& 5 & 71 & 227 & 152.09 & 142.00 & $10.4 \%$ \\
& 8 & 71 & 162 & 113.45 & 119.00 & $10.4 \%$ \\
& 9 & 57 & 140 & 100.88 & 109.00 & $7.5 \%$ \\
\hline
\end{tabular}

Source: Field Survey and Authors' Calculations, 2009.

Annex C6: Average RCCSI Score (Strata-wise)

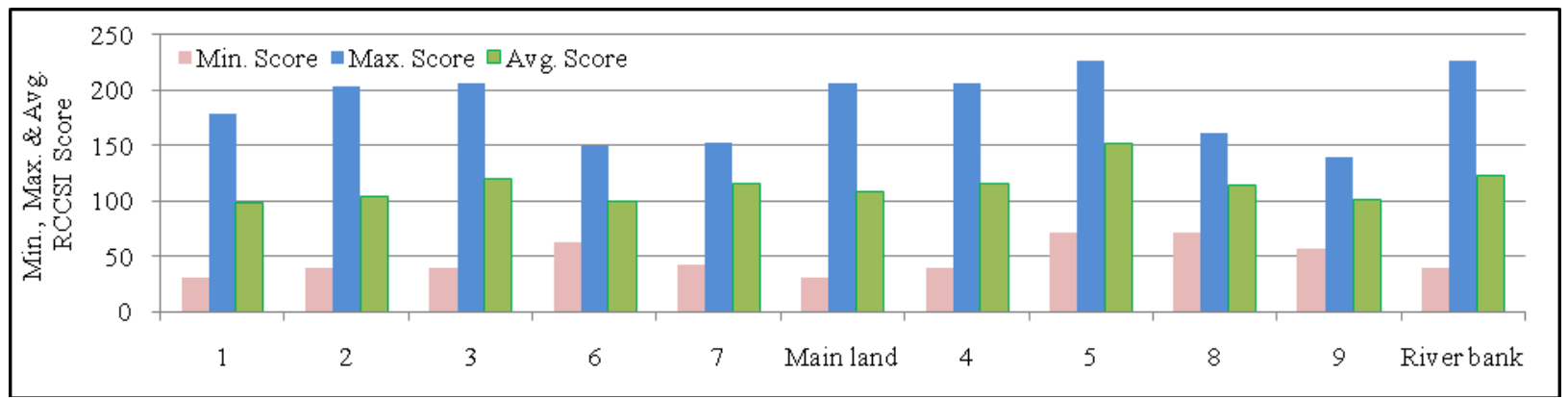

Source: Field Survey and Authors' Calculations, 2010. 
Annex C7: Reduced Consumption Coping Strategy Index at Lean period, RCCSI (\%)

\begin{tabular}{|c|c|c|c|c|c|c|c|c|c|c|c|}
\hline \multirow{2}{*}{ Question } & \multirow{2}{*}{$\begin{array}{l}\text { Answer } \\
\text { Codes }\end{array}$} & \multicolumn{9}{|c|}{ Strata (PSU) } & \multirow{2}{*}{ Total } \\
\hline & & 1 & 2 & 3 & 4 & 5 & 6 & 7 & 8 & 9 & \\
\hline \multirow{4}{*}{ 1. Less preferred } & 0 & 1.9 & 0.9 & 0.0 & 0.0 & 0.0 & 0.0 & 0.0 & 0.0 & 0.0 & 2.8 \\
\hline & 1.5 & 0.0 & 0.0 & 0.9 & 0.9 & 0.0 & 0.0 & 0.9 & 0.0 & 0.0 & 2.8 \\
\hline & 4.5 & 2.8 & 3.8 & 0.0 & 0.0 & 0.0 & 1.9 & 0.0 & 0.0 & 0.9 & 9.4 \\
\hline & 7 & 4.7 & 10.4 & 15.1 & 8.5 & 10.4 & 11.3 & 7.5 & 10.4 & 6.6 & 84.9 \\
\hline \multirow[t]{5}{*}{ 2. Borrow } & 0 & 0.0 & 0.0 & 0.0 & 0.0 & 0.0 & 0.0 & 0.9 & 0.0 & 0.0 & 0.9 \\
\hline & 0.5 & 0.9 & 0.0 & 0.0 & 0.0 & 0.0 & 0.0 & 0.0 & 0.0 & 0.0 & 0.9 \\
\hline & 1.5 & 4.7 & 1.9 & 1.9 & 2.8 & 0.9 & 4.7 & 1.9 & 0.9 & 1.9 & 21.7 \\
\hline & 4.5 & 2.8 & 13.2 & 8.5 & 6.6 & 3.8 & 6.6 & 4.7 & 8.5 & 4.7 & 59.4 \\
\hline & 7 & 0.9 & 0.0 & 5.7 & 0.0 & 5.7 & 1.9 & 0.9 & 0.9 & 0.9 & 17.0 \\
\hline \multirow[t]{5}{*}{ 3. Buy on credit } & 0 & 1.9 & 0.0 & 0.9 & 0.0 & 0.9 & 0.9 & 0.0 & 0.0 & 0.0 & 4.7 \\
\hline & 0.5 & 0.0 & 0.9 & 0.9 & 0.9 & 0.0 & 0.9 & 0.0 & 0.0 & 0.9 & 4.7 \\
\hline & 1.5 & 4.7 & 2.8 & 1.9 & 3.8 & 4.7 & 4.7 & 0.9 & 3.8 & 1.9 & 29.2 \\
\hline & 4.5 & 1.9 & 9.4 & 12.3 & 4.7 & 3.8 & 5.7 & 5.7 & 6.6 & 4.7 & 54.7 \\
\hline & 7 & 0.9 & 1.9 & 0.0 & 0.0 & 0.9 & 0.9 & 1.9 & 0.0 & 0.0 & 6.6 \\
\hline \multirow[t]{5}{*}{ 4. Wild food } & 0 & 0.0 & 1.9 & 0.0 & 0.0 & 0.0 & 0.0 & 0.0 & 0.0 & 0.0 & 1.9 \\
\hline & 0.5 & 0.0 & 0.9 & 0.0 & 0.0 & 0.0 & 0.0 & 0.0 & 0.0 & 0.0 & 0.9 \\
\hline & 1.5 & 2.8 & 1.9 & 0.0 & 0.9 & 0.9 & 0.0 & 0.0 & 0.0 & 0.0 & 6.6 \\
\hline & 4.5 & 5.7 & 5.7 & 4.7 & 2.8 & 1.9 & 9.4 & 3.8 & 6.6 & 4.7 & 45.3 \\
\hline & 7 & 0.9 & 4.7 & 11.3 & 5.7 & 7.5 & 3.8 & 4.7 & 3.8 & 2.8 & 45.3 \\
\hline \multirow[t]{5}{*}{ 5. Eat seed food } & 0 & 4.7 & 7.5 & 11.3 & 2.8 & 3.8 & 6.6 & 4.7 & 5.7 & 6.6 & 53.8 \\
\hline & 0.5 & 0.9 & 0.0 & 0.0 & 0.0 & 0.0 & 0.0 & 0.0 & 0.0 & 0.0 & 0.9 \\
\hline & 1.5 & 0.9 & 2.8 & 2.8 & 2.8 & 3.8 & 5.7 & 1.9 & 1.9 & 0.0 & 22.6 \\
\hline & 4.5 & 1.9 & 3.8 & 1.9 & 3.8 & 0.9 & 0.9 & 1.9 & 2.8 & 0.9 & 18.9 \\
\hline & 7 & 0.9 & 0.9 & 0.0 & 0.0 & 1.9 & 0.0 & 0.0 & 0.0 & 0.0 & 3.8 \\
\hline \multirow[t]{5}{*}{ 6. HH eat elsewhere } & 0 & 0.9 & 3.8 & 0.9 & 0.9 & 0.0 & 0.0 & 0.9 & 0.0 & 0.0 & 7.5 \\
\hline & 0.5 & 0.0 & 0.0 & 0.0 & 0.0 & 0.0 & 0.9 & 0.0 & 0.0 & 0.0 & 0.9 \\
\hline & 1.5 & 1.9 & 4.7 & 0.0 & 0.0 & 0.9 & 0.0 & 1.9 & 0.0 & 0.9 & 10.4 \\
\hline & 4.5 & 2.8 & 0.9 & 5.7 & 5.7 & 0.9 & 8.5 & 1.9 & 6.6 & 5.7 & 38.7 \\
\hline & 7 & 3.8 & 5.7 & 9.4 & 2.8 & 8.5 & 3.8 & 3.8 & 3.8 & 0.9 & 42.5 \\
\hline \multirow[t]{2}{*}{ 7. Limit portion } & 0 & 8.5 & 15.1 & 16.0 & 9.4 & 10.4 & 13.2 & 8.5 & 10.4 & 7.5 & 99.1 \\
\hline & 1.5 & 0.9 & 0.0 & 0.0 & 0.0 & 0.0 & 0.0 & 0.0 & 0.0 & 0.0 & 0.9 \\
\hline \multirow[t]{5}{*}{ 8. Restrict adult intake } & 0 & 7.5 & 13.2 & 16.0 & 8.5 & 7.5 & 13.2 & 8.5 & 10.4 & 7.5 & 92.5 \\
\hline & 0.5 & 0.0 & 0.9 & 0.0 & 0.0 & 0.9 & 0.0 & 0.0 & 0.0 & 0.0 & 1.9 \\
\hline & 1.5 & 0.0 & 0.9 & 0.0 & 0.0 & 0.0 & 0.0 & 0.0 & 0.0 & 0.0 & 0.9 \\
\hline & 4.5 & 1.9 & 0.0 & 0.0 & 0.0 & 0.0 & 0.0 & 0.0 & 0.0 & 0.0 & 1.9 \\
\hline & 7 & 0.0 & 0.0 & 0.0 & 0.9 & 1.9 & 0.0 & 0.0 & 0.0 & 0.0 & 2.8 \\
\hline \multirow[t]{5}{*}{ 9. Reduce meals } & 0 & 2.8 & 0.9 & 0.0 & 0.9 & 1.9 & 3.8 & 4.7 & 4.7 & 1.9 & 21.7 \\
\hline & 0.5 & 0.0 & 3.8 & 1.9 & 2.8 & 0.0 & 0.9 & 0.0 & 0.0 & 0.0 & 9.4 \\
\hline & 1.5 & 5.7 & 7.5 & 11.3 & 3.8 & 5.7 & 8.5 & 0.9 & 5.7 & 4.7 & 53.8 \\
\hline & 4.5 & 0.9 & 1.9 & 2.8 & 1.9 & 2.8 & 0.0 & 2.8 & 0.0 & 0.9 & 14.2 \\
\hline & 7 & 0.0 & 0.9 & 0.0 & 0.0 & 0.0 & 0.0 & 0.0 & 0.0 & 0.0 & 0.9 \\
\hline \multirow[t]{5}{*}{ 10. Skip days } & 0 & 7.5 & 8.5 & 14.2 & 7.5 & 2.8 & 12.3 & 6.6 & 7.5 & 6.6 & 73.6 \\
\hline & 0.5 & 0.0 & 3.8 & 0.9 & 0.9 & 0.9 & 0.0 & 0.0 & 0.0 & 0.0 & 6.6 \\
\hline & 1.5 & 0.9 & 1.9 & 0.0 & 0.9 & 3.8 & 0.9 & 0.9 & 2.8 & 0.9 & 13.2 \\
\hline & 4.5 & 0.9 & 0.0 & 0.0 & 0.0 & 2.8 & 0.0 & 0.9 & 0.0 & 0.0 & 4.7 \\
\hline & 7 & 0.0 & 0.9 & 0.9 & 0.0 & 0.0 & 0.0 & 0.0 & 0.0 & 0.0 & 1.9 \\
\hline
\end{tabular}

Source: Field Survey and Authors' Calculations, 2010. 
Annex D: Econometric Model Estimation

Annex D1: Sources and Definitions of Interval Regression Model Variables

\begin{tabular}{|c|c|c|}
\hline Variable & Type & Description \\
\hline \multicolumn{3}{|c|}{ Dependent Variable } \\
\hline lccsi & Continuous & $\begin{array}{l}\text { Lower interval score of reduced consumption coping } \\
\text { strategies index }\end{array}$ \\
\hline uccsi & Continuous & $\begin{array}{l}\text { Upper interval score of reduced consumption coping } \\
\text { strategies index }\end{array}$ \\
\hline \multicolumn{3}{|c|}{ Category Variables } \\
\hline hhh_ps_1 & Binary & $\begin{array}{l}1 \text { if household head attended primary school, otherwise } \\
0\end{array}$ \\
\hline hhh_age & Continuous & Age of household head \\
\hline pcmfe_mp & Continuous & Per capita monthly food expenditure at lean period \\
\hline tot_mem & Continuous & $\begin{array}{l}\text { Total family member including all member in home and } \\
\text { outside of home }\end{array}$ \\
\hline paddy_d & Continuous & $\begin{array}{l}\text { Fulfill of paddy demand at a year (in days) by own } \\
\text { production }\end{array}$ \\
\hline p_ass_val & Continuous & $\begin{array}{l}\text { Total value of asset (for production purposes) of } \\
\text { household }\end{array}$ \\
\hline ssnp_govt_1 & Binary & $\begin{array}{l}1 \text { if household under government's social safety net } \\
\text { programme, otherwise } 0\end{array}$ \\
\hline hh_loan_1 & Binary & $\begin{array}{l}1 \text { if household have loan from different sources, } \\
\text { otherwise } 0\end{array}$ \\
\hline river bank 1 & Binary & 1 if household besides riverbank, otherwise 0 \\
\hline
\end{tabular}

Source: Authors' Compilations, 2010.

Annex D2: Summery Statistics

\begin{tabular}{llrrr}
\hline Variable & Obs. & Std. Err. & Min & Max \\
\hline lccsi & 106 & 38.31 & 30 & 210 \\
uccsi & 105 & 37.00 & 50 & 210 \\
hhh_ps_1 & 106 & 0.39 & 0 & 1 \\
hhh_age & 106 & 16.56 & 24 & 110 \\
pcmfe_mp & 106 & 676.50 & 162.75 & 4392 \\
tot_mem & 106 & 1.46 & 1 & 8 \\
paddy_d & 106 & 78.06 & 0 & 300 \\
p_ass_val & 106 & 7651.38 & 0 & 39000 \\
ssnp_govt_1 & 106 & 0.47 & 0 & 1 \\
hh_loan_1 & 106 & 0.50 & 0 & 1 \\
river_bank_1 & 106 & 0.49 & 0 & 1 \\
\hline
\end{tabular}

Source: Field Survey and Authors' Calculations, 2010. 
Annex D3: Correlation Matrix of Coefficients of Interval Regression Model

\begin{tabular}{|c|c|c|c|c|c|c|c|c|c|c|c|}
\hline & hhh_ps_1 & hhh_age & pcmfe_mp & tot_mem & paddy_d & p_ass_val & ssnp_govt_1 & hh_loan_1 & river_bank_1 & $1 \mathrm{ccsi}$ & uccsi \\
\hline hhh_ps_1 & 1.00 & & & & & & & & & & \\
\hline hhh_age & -0.11 & 1.00 & & & & & & & & & \\
\hline pcmfe_mp & -0.03 & 0.23 & 1.00 & & & & & & & & \\
\hline tot_mem & -0.02 & -0.06 & -0.68 & 1.00 & & & & & & & \\
\hline paddy_d & -0.08 & -0.06 & -0.01 & 0.01 & 1.00 & & & & & & \\
\hline p_ass_val & 0.10 & 0.24 & -0.04 & 0.16 & 0.07 & 1.00 & & & & & \\
\hline ssnp_govt_1 & -0.02 & 0.12 & 0.07 & 0.00 & 0.09 & 0.06 & 1.00 & & & & \\
\hline hh_loan_1 & -0.09 & -0.06 & -0.05 & 0.10 & -0.03 & 0.02 & 0.05 & 1.00 & & & \\
\hline river_bank_1 & 0.13 & 0.01 & 0.31 & -0.14 & 0.02 & 0.15 & 0.02 & 0.12 & 1.00 & & \\
\hline lecsi & -0.11 & -0.06 & 0.15 & -0.15 & -0.21 & -0.20 & 0.19 & 0.08 & 0.17 & 1.00 & \\
\hline uccsi & -0.11 & -0.06 & 0.15 & -0.15 & -0.21 & -0.20 & 0.19 & 0.08 & 0.17 & 1.00 & 1.00 \\
\hline
\end{tabular}

Source: Field Survey and Authors' Calculations, 2010.

Annex D4: Econometric Estimation

\begin{tabular}{|c|c|c|c|}
\hline \multirow[t]{2}{*}{ Category Variables } & \multicolumn{3}{|c|}{ Interval Regression } \\
\hline & Coefficient & Robust Std. Err. & $\mathrm{Z}$ \\
\hline hhh ps 1 & $-13.80 * *$ & 7.22 & -1.91 \\
\hline hhh_age & -0.17 & 0.22 & -0.78 \\
\hline pcmfe_mp & -0.0002 & 0.01 & -0.02 \\
\hline tot_mem & -1.62 & 3.20 & -0.51 \\
\hline pad̄dy_d & $-0.11 * * *$ & 0.04 & -2.82 \\
\hline p_ass_val & $-0.001 * * *$ & 0.0003 & -2.85 \\
\hline ssnp_govt_1 & $16.37 * *$ & 7.02 & 2.33 \\
\hline hh_loan_1 & 4.17 & 7.25 & 0.58 \\
\hline river_bank_1 & $18.48 * *$ & 9.04 & 2.04 \\
\hline Cons. & $123.27 * * *$ & 19.68 & 6.26 \\
\hline /Insigma & $3.52 * * *$ & 0.08 & 46.20 \\
\hline Sigma & 33.72 & 2.57 & \\
\hline Wald chi2 (9) & 39.57 & & \\
\hline Prob $>$ chi 2 & 0.0000 & & \\
\hline
\end{tabular}

$* * *, * *, *$ : Significant at $1 \%, 5 \%$ and $10 \%$ level.

Source: Field Survey and Authors' Calculations, 2010. 
Annex E: Distribution of Body Mass Index (BMI, Strata-wise)

\begin{tabular}{cccccc}
\hline \multirow{2}{*}{$\begin{array}{c}\text { Strata } \\
\text { Type }\end{array}$} & Strata & \multicolumn{5}{c}{ BMI Rank } \\
\cline { 2 - 6 } & & $\begin{array}{c}2 \\
\text { (Underweight) }\end{array}$ & $\begin{array}{c}2 \\
\text { (Healthy Weight) }\end{array}$ & $\begin{array}{c}3 \\
\text { (Overweight) }\end{array}$ & Total \\
\hline \multirow{5}{*}{ Mainland } & 1 & 6 & 4 & 0 & 10 \\
& 2 & 11 & 4 & 0 & 15 \\
& 3 & 10 & 5 & 0 & 15 \\
& 6 & 3 & 7 & 1 & 11 \\
\cline { 2 - 6 } & 7 & 2 & 6 & 0 & 8 \\
\hline \multirow{5}{*}{ Riverbank } & Total & $32(54.24 \%$ of 59$)$ & 26 & 0 & 59 \\
& 5 & 4 & 5 & 0 & 9 \\
& 8 & 6 & 3 & 0 & 8 \\
& 9 & 4 & 4 & 0 & 4 \\
\hline
\end{tabular}

Source: Field Survey and Authors' Calculations, 2010.

Annex F: Distribution of Household's Dependency Ratio (Strata-wise)

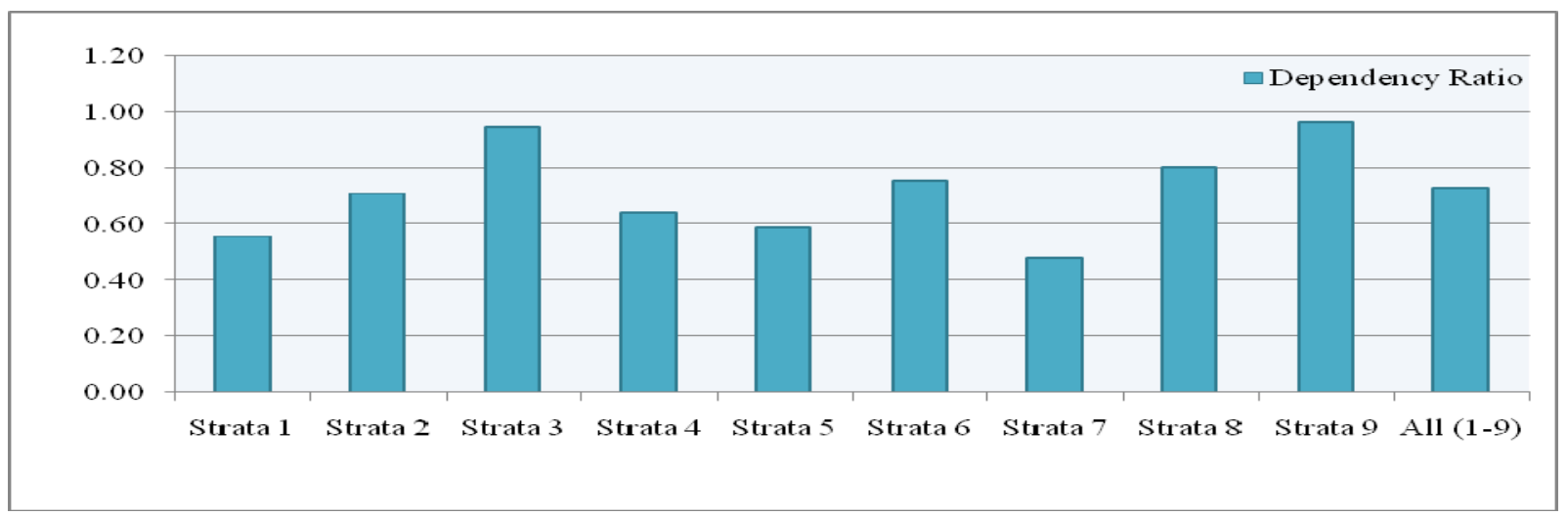

Source: Field Survey and Authors' Calculations, 2010. 